\title{
Perfilhamento e produtividade de cana-de-açúcar com diferentes alturas de corte e épocas de colheita
}

\author{
Marcelo de Almeida Silva(1), Elisangela Marques Jeronimo(1) e Alessandro Dal'Col Lúcio(2)
}

\begin{abstract}
(1)Agência Paulista de Tecnologia dos Agronegócios, Centro-Oeste, Caixa Postal 66, CEP 17201-970 Jaú, SP. E-mail: marcelosilva@apta.sp.gov.br, elijeronimo@apta.sp.gov.br ${ }^{(2)}$ Universidade Federal de Santa Maria, Departamento de Fitotecnia, Avenida Roraima, s/no, Bairro Camobi, CEP 97105-900 Santa Maria, RS. E-mail: adlucio@smail.ufsm.br
\end{abstract}

Resumo - O objetivo deste trabalho foi avaliar a relação entre a altura do corte basal de colmos e da época de colheita da cana-de-açúcar e suas conseqüências no perfilhamento e na produtividade da cana-soca. O delineamento experimental foi o de blocos ao acaso, em fatorial $2 \times 3 \times 3$, constituídos de dois genótipos (IAC86-2480 e RB72454), três alturas de corte (0, 10 e $20 \mathrm{~cm}$, acima do nível do solo) e três épocas de colheita (maio, julho e setembro de 2006), com quatro repetições, em Jaú, SP. O 'IAC86-2480' mostrou maior número de perfilhos por metro linear, em relação ao 'RB72454', em todas as avaliações. No final do ciclo de desenvolvimento, as alturas de cortes de 10 e $20 \mathrm{~cm}$ e a época de colheita em maio proporcionaram maior número de perfilhos. Os genótipos de cana-de-açúcar responderam à altura de corte e à época de colheita dos colmos. O 'RB72454' teve maior produtividade de cana, quando a colheita foi realizada em setembro. A reserva energética acumulada na base dos colmos favoreceu a rebrota da cana-de-açúcar, em condições climáticas desfavoráveis. A época de colheita interferiu na produtividade de cana e de açúcar.

Termos para indexação: Saccharum, brotação, cana-soca, genótipos, produção.

\section{Height of cut and harvest period effects on tillering and yield of sugarcane}

\begin{abstract}
The objective of this work was to evaluate the relationship of sugarcane cut height cane and harvest period, and their effects on tillering and ratoon yield. The experimental design was the randomized blocks one, in a $2 \times 3 \times 3$ factorial arrangement, with two genotypes (IAC86-2480 and RB72454), three heights of cut (0, 10 and $20 \mathrm{~cm}$, above soil level) and three harvest periods (May, July and September 2006), with four replicates, in Jaú, São Paulo State, Brazil. Tillering was significantly higher in 'IAC86-2480', in comparison to 'RB72454', in all evaluations. At the end of the growth cycle, cut heights at 10 and $20 \mathrm{~cm}$ of fields harvested in May resulted in higher tillering. Sugarcane genotypes responded to heights of cut and to harvest periods. The highest cane yield was observed in 'RB72454' harvested in September. The energy stored in the base of stalks improved sugarcane sprouting under unfavorable weather conditions. Season periods affected stalk and sugar yield.
\end{abstract}

Index terms: Saccharum, sprouting, ratoon cane, genotypes, production.

\section{Introdução}

A cana-de-açúcar é colhida de abril a novembro, nos diferentes ambientes de produção da região Centro-Sul do Brasil. O planejamento de colheita na cultura busca otimizar seu retorno econômico, com base no conceito de que a cana tem uma época, durante o ano, que é mais propícia para a colheita.

Diversos fatores podem interferir na produtividade e na qualidade tecnológica da cana-de-açúcar que, no final, representa a integração das diferentes condições a que a cultura ficou sujeita (Gilbert et al., 2006). A cada ciclo de desenvolvimento, a cultura é submetida a diferentes condições ambientais e a manejos empregados, em relação à época de plantio, variedade, época e tipo de colheita e estágio de desenvolvimento da cultura. Em conseqüência destas e de outras causas de variação ao longo do ciclo, surge a necessidade de previsão das respostas da cultura a diferentes estímulos (Marchiori, 2004).

Entre as inúmeras medidas de manejo, que podem permitir ganhos reais de produtividade da lavoura, a época de colheita tem merecido atenção especial. Rezende Sobrinho (2000) afirma que o aumento da produtividade, no setor sucroalcooleiro, é conseguido com a introdução de novas variedades de cana-deaçúcar e com manejo correto da cultura, buscando a época de colheita em que a produtividade agroindustrial se encontra maximizada. 
A colheita mecanizada da cana-de-açúcar está cada vez mais presente nos sistemas de produção no Brasil (Souza et al., 2005). A colheita do colmo é feita por meio do corte basal e apical (desponte); o primeiro pode ser realizado pela colhedora em diferentes alturas, a depender de fatores como regulagem das facas e das condições do terreno, pois, conforme a topografia, há maior ou menor aproveitamento da matéria-prima.

O colmo da cana constitui-se num reservatório onde é acumulada grande quantidade de sacarose, principalmente nos internódios basais (Casagrande, 1991). Após se efetuar a colheita dos colmos, tem início a brotação da soca, e um novo processo de perfilhamento é estabelecido. A brotação constitui fase importante, pois uma boa brotação reflete um bom começo, que trará à área cultivada plantas vigorosas, que resultarão, no final do ciclo, em colheita compensadora (Silva et al., 2003, 2004). A boa capacidade de brotação é uma característica desejável nas variedades, principalmente quando essa fase envolve épocas com condições ambientais desfavoráveis (Casagrande, 1991).

Para a brotação das soqueiras, deve-se considerar como fundamental, segundo Carneiro et al. (1995), a reserva em rizomas ou colmos subterrâneos (parte basal do colmo, que permanece enterrada no solo após o corte da cana) e raízes remanescentes do ciclo anterior. Casagrande (1991) afirmou que, nos primeiros 30 dias, quando ocorre a emissão de raízes de fixação e brotação de gemas, a cana-planta vive da reserva de nutrientes do tolete, que é redistribuída, e parcialmente dos nutrientes absorvidos pelas raízes de fixação. Após esse período, segundo o mesmo autor, inicia-se o desenvolvimento das raízes dos perfilhos primários, depois dos secundários, e assim sucessivamente, então as raízes de fixação perdem a função, e a cana-planta passa a depender exclusivamente da atividade das raízes dos perfilhos.

Assim, durante a colheita mecanizada, se pedaços de colmos basais não colhidos ficarem na superfície do solo, esses poderão servir como reserva energética para potencializar a rebrota, principalmente em condições climáticas desfavoráveis. Pela importância da altura do corte basal dos colmos e da época de colheita, no processo de produção da cana-de-açúcar, o objetivo deste trabalho foi avaliar essa relação e seus reflexos, no perfilhamento e na produtividade da cana-soca seguinte.

\section{Material e Métodos}

A pesquisa foi desenvolvida em área da Unidade de Pesquisa e Desenvolvimento de Jaú (SP), da Agência Paulista de Tecnologia dos Agronegócios Centro-Oeste, a $22^{\circ} 17^{\prime} \mathrm{S}$ e $48^{\circ} 34^{\prime} \mathrm{W}$, à altitude de $580 \mathrm{~m}$. O solo da área é Latossolo Vermelho eutroférrico, com A moderado e textura argilosa (Prado, 2003). O clima predominante da região é o Aw (Köppen), seco definido nos meses de inverno, temperatura média anual de $21,6^{\circ} \mathrm{C}$, com umidade relativa média mensal de $70 \%$, com extremos de $99 \%$ em fevereiro e $19 \%$ em agosto. A média pluviométrica anual é de $1.344 \mathrm{~mm}$.

Utilizou-se o delineamento de blocos ao acaso, em esquema fatorial $2 \times 3 \times 3$, constituídos de dois genótipos (IAC86-2480 e RB72454), três alturas de corte $(0,10$ e $20 \mathrm{~cm}$, acima da superfície do solo) e três épocas de colheita (15 de maio, 17 de julho e 18 de setembro de 2006), com quatro repetições. Os tratamentos de $10 \mathrm{e}$ $20 \mathrm{~cm}$, acima da superfície do solo, foram estabelecidos com a ajuda de um gabarito de barbante, posicionado nas alturas determinadas, e pelo corte dos colmos efetuado por meio de roçadeira, equipada com lâmina de corte de $200 \mathrm{~mm}$ de diâmetro, com 22 dentes de cinzel. Cada unidade experimental foi constituída de cinco sulcos de seis metros de comprimento, distanciados entre si por $1,4 \mathrm{~m}$.

O plantio da área foi realizado em 22 de abril de 2004, com adubação de $16 \mathrm{~kg} \mathrm{ha}^{-1}$ de $\mathrm{N}$ e $80 \mathrm{~kg} \mathrm{ha}^{-1}$ de $\mathrm{P}_{2} \mathrm{O}_{5}$ e de $\mathrm{K}_{2} \mathrm{O}$, com a fórmula 4-20-20. Para o controle de pragas de solo, foram aplicados no sulco, antes do plantio, $136 \mathrm{~g}$ de i.a. de fipronil $+875 \mathrm{~g}$ de i.a. de carbofuran, em $50 \mathrm{~L}$ de água, na área útil. $\mathrm{Na}$ cana-soca, após 30 dias do primeiro corte, foram aplicados, na entrelinha de cana, $80 \mathrm{~kg} \mathrm{ha}^{-1} \mathrm{de} \mathrm{N}$ e de $\mathrm{K}_{2} \mathrm{O}$, e $20 \mathrm{~kg} \mathrm{ha}^{-1}$ de $\mathrm{P}_{2} \mathrm{O}_{5}$, da fórmula 20-5-20, para cultivo da soqueira. Os cortes foram efetuados em 16 de junho, 18 de agosto e 19 de outubro de 2005, nas áreas destinadas para a primeira, segunda e terceira épocas de colheita, respectivamente, com a finalidade de se uniformizar a idade de colheita, em cada época proposta para o estudo, em 11 meses.

Onúmerode colmosindustrializáveis foi determinado pela contagem dos colmos dentro de cada parcela, aos 0, 90, 180, 270 e 360 dias após a implantação dos tratamentos (DAT) de época de colheita. No tempo 0 DAT, foram considerados os números de perfilhos, determinados na contagem realizada no dia anterior ao corte da parcela. 
A avaliação da produtividade de colmos (TCH), em cada época de colheita, foi feita pela obtenção da massa $(\mathrm{kg})$ da parcela, com balança tipo célula de carga, graduada em $200 \mathrm{~g}$. Foram somadas à massa final as massas de cada feixe retirado para avaliação da qualidade tecnológica. A produtividade de cana foi calculada por meio da massa de todos os colmos industrializáveis por parcela e da área ocupada por cada parcela $\left(\mathrm{Mg} \mathrm{ha}^{-1}\right)$.

Para determinação dos atributos de qualidade, foi obtida uma amostra de dez colmos, coletados seguida e aleatoriamente dos cinco sulcos de cada parcela. Foi coletada a massa de cada feixe de dez colmos. Posteriormente, essas amostras foram encaminhadas ao Laboratório de Tecnologia da Associcana, Jaú (SP), para as análises e obtenção dos valores de sacarose (pol) da cana, percentagem de fibra da cana, e açúcar total recuperável (ATR, $\mathrm{kg} \mathrm{Mg}^{-1}$ ). A produtividade de açúcar (TPH) foi obtida por meio do produto entre a TCH e a concentração de sacarose (pol cana) correspondente de cada parcela, dividido por 100 .

Para verificar o efeito dos fatores sobre as plantas, foram realizadas análises de variância, com o teste de
Tukey, a 5\% de probabilidade, para a comparação das médias.

\section{Resultados e Discussão}

Os dados mensais de temperaturas médias máximas e mínimas e de precipitação, em escala decendial, durante a condução do experimento, nas safras 2004/2005, 2005/2006 e 2006/2007 são apresentados na Figura 1. Houve pouca quantidade de chuva, $24 \mathrm{~mm}$, e baixas temperaturas - média máxima, $26^{\circ} \mathrm{C}$, e média mínima, $12^{\circ} \mathrm{C}$-, entre as datas da primeira $(15 / 5 / 2006)$ e segunda (16/7/2006) época de colheita. Entre a segunda e terceira (17/9/2006) épocas de colheita, o volume de chuva registrado foi de $91 \mathrm{~mm}$, e as temperaturas médias máximas e mínimas foram $32 \mathrm{e}$ $15^{\circ} \mathrm{C}$, respectivamente. Até dois meses após a colheita da terceira época, foram registrados $199 \mathrm{~mm}$ de chuva, com temperaturas médias máximas e mínimas de 30 e $17^{\circ} \mathrm{C}$, respectivamente. Portanto, as condições climáticas se tornaram mais propícias e favoráveis à brotação da cana-de-açúcar, conforme a época de corte, no transcorrer do estudo.

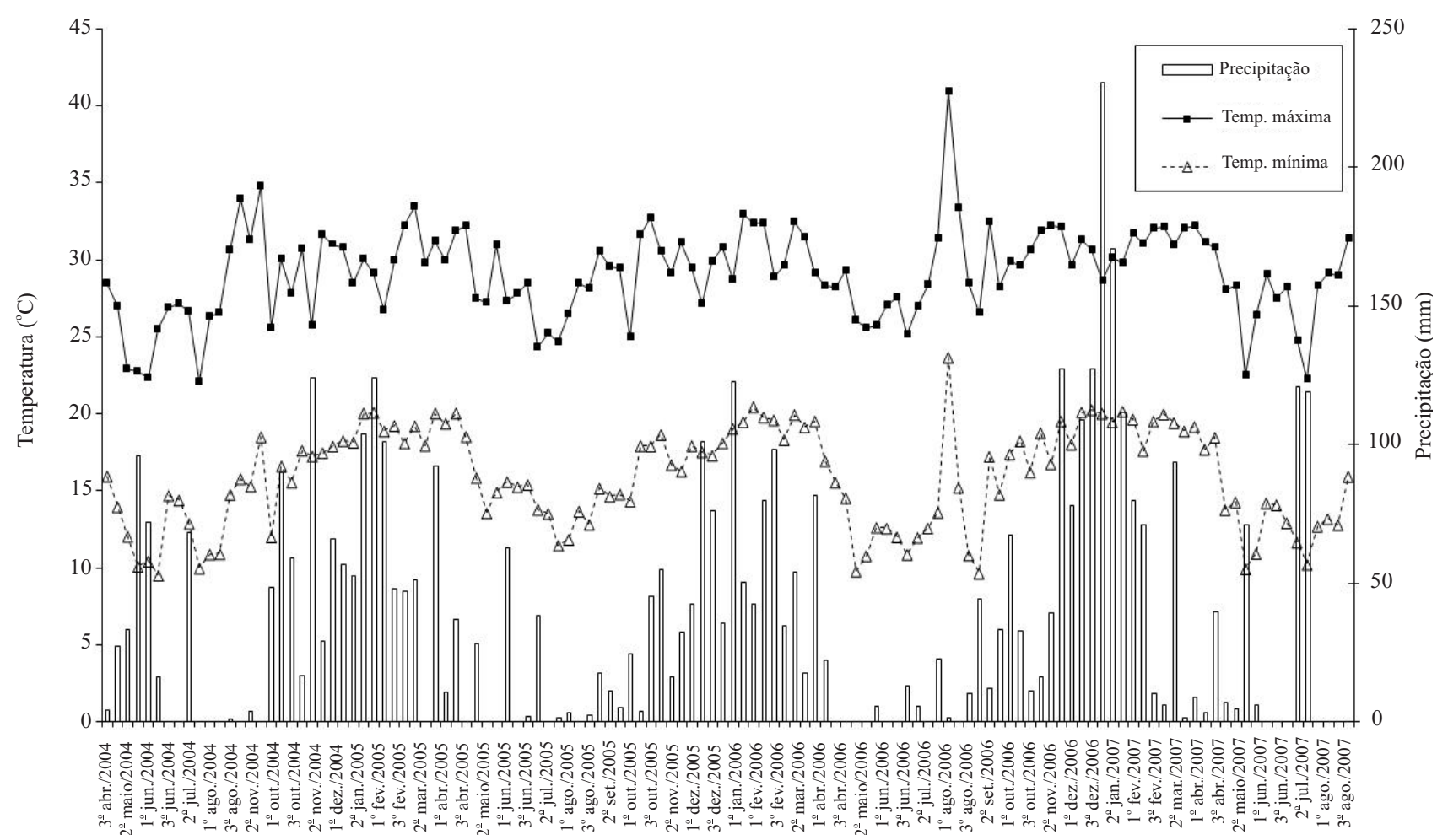

Figura 1. Temperaturas médias máximas e mínimas $\left({ }^{\circ} \mathrm{C}\right)$ e precipitação $(\mathrm{mm})$, em escala decendial, observadas em Jaú, SP, nas safras 2004/2005, 2005/2006 e 2006/2007. 
A análise da variância indicou a significância das causas de variação relacionadas aos genótipos, às alturas de corte e às épocas de colheita, relativas à variável perfilhamento, em todas as épocas avaliadas (Tabela 1).

O genótipo IAC86-2480 mostrou maior número de perfilhos por metro linear, em relação ao 'RB72454', em todas as avaliações. A altura de corte realizada a $20 \mathrm{~cm}$ acima do solo proporcionou maior perfilhamento, em comparação às demais alturas $\left(\begin{array}{llll}0 & \text { e } & 10 & \mathrm{~cm}\end{array}\right)$, dos 90 aos 270 dias após o início dos tratamentos (DAT), enquanto o corte efetuado a $10 \mathrm{~cm}$ acima do solo diferenciou-se do realizado a $0 \mathrm{~cm}$, nesse mesmo período. Aos 360 DAT, houve diferença apenas entre as alturas de corte de 0 e $10 \mathrm{~cm}$. Quanto à época de colheita, o perfilhamento foi maior aos 90 DAT, quando a colheita foi feita em setembro; entretanto, a colheita feita em maio favoreceu o número de perfilhos, dos 180 até os 360 DAT. Assim, na colheita seguinte, no final do ciclo aos 360 DAT, as alturas de cortes de 10 e $20 \mathrm{~cm}$ e a época de colheita em maio proporcionaram maior número de perfilhos. Esses resultados indicam que houve resposta do perfilhamento, numa época desfavorável à brotação (Figura 1), quando havia

Tabela 1. Número de perfilhos de cana-de-açúcar por metro linear, em relação a genótipos, altura de corte e época de colheita, aos $0,90,180,270$ e 360 dias após implantação dos tratamentos ${ }^{(1)}$.

\begin{tabular}{|c|c|c|c|c|c|}
\hline \multirow[t]{2}{*}{ Tratamento } & \multicolumn{5}{|c|}{ Dias após implantação } \\
\hline & 0 & 90 & 180 & 270 & 360 \\
\hline \multicolumn{6}{|l|}{ Genótipo } \\
\hline IAC86-2480 & $11,16 \mathrm{a}$ & $29,18 \mathrm{a}$ & $20,24 a$ & $14,20 \mathrm{a}$ & $12,00 \mathrm{a}$ \\
\hline RB72454 & & $18,77 \mathrm{~b}$ & 16 & $13,11 \mathrm{~b}$ & $10,99 \mathrm{~b}$ \\
\hline \multicolumn{6}{|l|}{ Altura de corte $(\mathrm{cm})$} \\
\hline 0 & $10,81 \mathrm{a}$ & $17,22 \mathrm{c}$ & $15,65 \mathrm{c}$ & $12,62 \mathrm{c}$ & $11,14 b$ \\
\hline 10 & $10,82 \mathrm{a}$ & $25,82 b$ & $18,90 \mathrm{~b}$ & $13,82 b$ & $11,77 \mathrm{a}$ \\
\hline 20 & $10,17 \mathrm{a}$ & $28,90 \mathrm{a}$ & $20,65 \mathrm{a}$ & $14,54 \mathrm{a}$ & $11,57 \mathrm{ab}$ \\
\hline \multicolumn{6}{|l|}{ Época de colheita } \\
\hline Maio & $12,00 \mathrm{a}$ & $18,77 \mathrm{c}$ & $22,79 \mathrm{a}$ & $17,41 \mathrm{a}$ & $12,89 \mathrm{a}$ \\
\hline Julho & $9,88 \mathrm{~b}$ & $24,15 b$ & $17,84 \mathrm{~b}$ & $12,17 \mathrm{~b}$ & $10,73 \mathrm{~b}$ \\
\hline Setembro & $9,92 b$ & $29,01 \mathrm{a}$ & $14,57 \mathrm{c}$ & $11,39 \mathrm{c}$ & $10,85 \mathrm{~b}$ \\
\hline \multicolumn{6}{|l|}{ Quadrados médios } \\
\hline Bloco & $4,37 *$ & $44,78^{*}$ & $6,90^{\mathrm{ns}}$ & $3,21 *$ & $3,83 *$ \\
\hline Genótipo $(\mathrm{G})$ & $22,86^{*}$ & $1.951,74^{*}$ & $242,61 *$ & $21,56^{*}$ & $18,60^{*}$ \\
\hline Altura de corte $(\mathrm{A})$ & $3,37 *$ & $879,89 *$ & $154,78^{*}$ & $22,50 *$ & $2,47 *$ \\
\hline Época de colheita (E) & $34,89^{*}$ & $629,91 *$ & $411,30^{*}$ & $257,41 *$ & $35,34 *$ \\
\hline GxA & $1,59^{\mathrm{ns}}$ & $31,68^{\mathrm{ns}}$ & $2,05^{\mathrm{ns}}$ & $4,00 *$ & $4,35^{*}$ \\
\hline $\mathrm{GxE}$ & $7,27 *$ & $131,90^{*}$ & $174,04 *$ & $9,55^{*}$ & $1,31^{\mathrm{ns}}$ \\
\hline $\mathrm{AxE}$ & $1,57^{\mathrm{ns}}$ & $24,17^{\mathrm{ns}}$ & $50,75^{*}$ & $17,26^{*}$ & $4,93^{*}$ \\
\hline GxExA & $1,53^{\text {ns }}$ & $7,47^{\mathrm{ns}}$ & $7,44^{\mathrm{ns}}$ & $0,98^{\mathrm{ns}}$ & $1,01^{\mathrm{ns}}$ \\
\hline CV (\%) & 9,17 & 13,86 & 13,18 & 7,23 & 7,11 \\
\hline
\end{tabular}

${ }^{(1)}$ Médias seguidas de letras iguais na coluna, em cada atributo (genótipo, altura de corte e época de colheita), não diferem entre si pelo teste de Tukey, a $5 \%$ de probabilidade. ${ }^{\text {ns Não-significativo. } * \text { Significativo }}$ a $5 \%$ de probabilidade. reserva nutricional nos pedaços de toletes deixados durante o corte.

Quanto às interações dessas causas de variação, verificou-se significância em genótipos x altura de corte, aos 270 e 360 DAT, em genótipos x época de colheita, de 0 aos 270 DAT, e em altura de corte $x$ época de colheita, dos 180 aos 360 DAT (Tabela 1). A evolução do perfilhamento dos genótipos, em conseqüência da altura de corte dos colmos, é apresentada na Figura 2. Nas alturas de 0 e $10 \mathrm{~cm}$ foi observado maior perfilhamento do 'IAC86-2480', em todas as avaliações. Com o corte realizado a $20 \mathrm{~cm}$ de altura, o 'IAC86-2480' também mostrou maior número de perfilhos por metro do que o 'RB72454' até os $180 \mathrm{DAT}$; aos 270 e 360 DAT, os valores se igualaram para os dois genótipos (Figura $2 \mathrm{C}$ ). Em todos os tratamentos, o número máximo de perfilhos foi obtido aos 90 dias, com exceção ao corte feito em maio. Isso mostra que o corte nessa época promoveu brotação mais lenta, em razão das condições de tempo adversas, entretanto, tal fato não prejudicou o desempenho no final da safra. Em todas as épocas, o número de perfilhos final foi muito próximo do inicial.

No desdobramento da interação entre genótipos e época de colheita, verificou-se que a colheita realizada em maio favoreceu o perfilhamento do 'IAC86-2480', durante todo o período do estudo, que se diferenciou do 'RB72454' (Figura 3). Observou-se, também, que a colheita feita em maio proporcionou aumento do perfilhamento de ambos os genótipos até 180 DAT, enquanto nas colheitas feitas em julho e setembro, esse aumento ocorreu num período de tempo menor, entre 0 e 90 DAT. De fato, esse aumento no perfilhamento, em até seis meses de idade, e posterior redução de cerca de $50 \%$, seguida de estabilização tanto em cana-planta quanto em cana-soca, a partir dos nove meses, é característica fisiológica da cana-de-açúcar, também observada em estudos realizados por vários autores (Castro \& Christofoleti, 2005; Silva et al., 2007).

Os efeitos da interação da altura de corte e da época de colheita estão representados na Figura 4. $\mathrm{Na}$ colheita feita em maio houve efeito significativo das diferentes alturas de corte (Figura 4 A). A altura de $20 \mathrm{~cm}$ promoveu maior perfilhamento, em relação a 0 e $10 \mathrm{~cm}$, no período de 90 aos 270 DAT. Ao completar 360 DAT, os perfilhamentos de 10 e 20 cm não diferiram, entretanto, foram maiores do que o obtido com o corte feito rente ao solo $(0 \mathrm{~cm})$. Na colheita de julho (segunda 

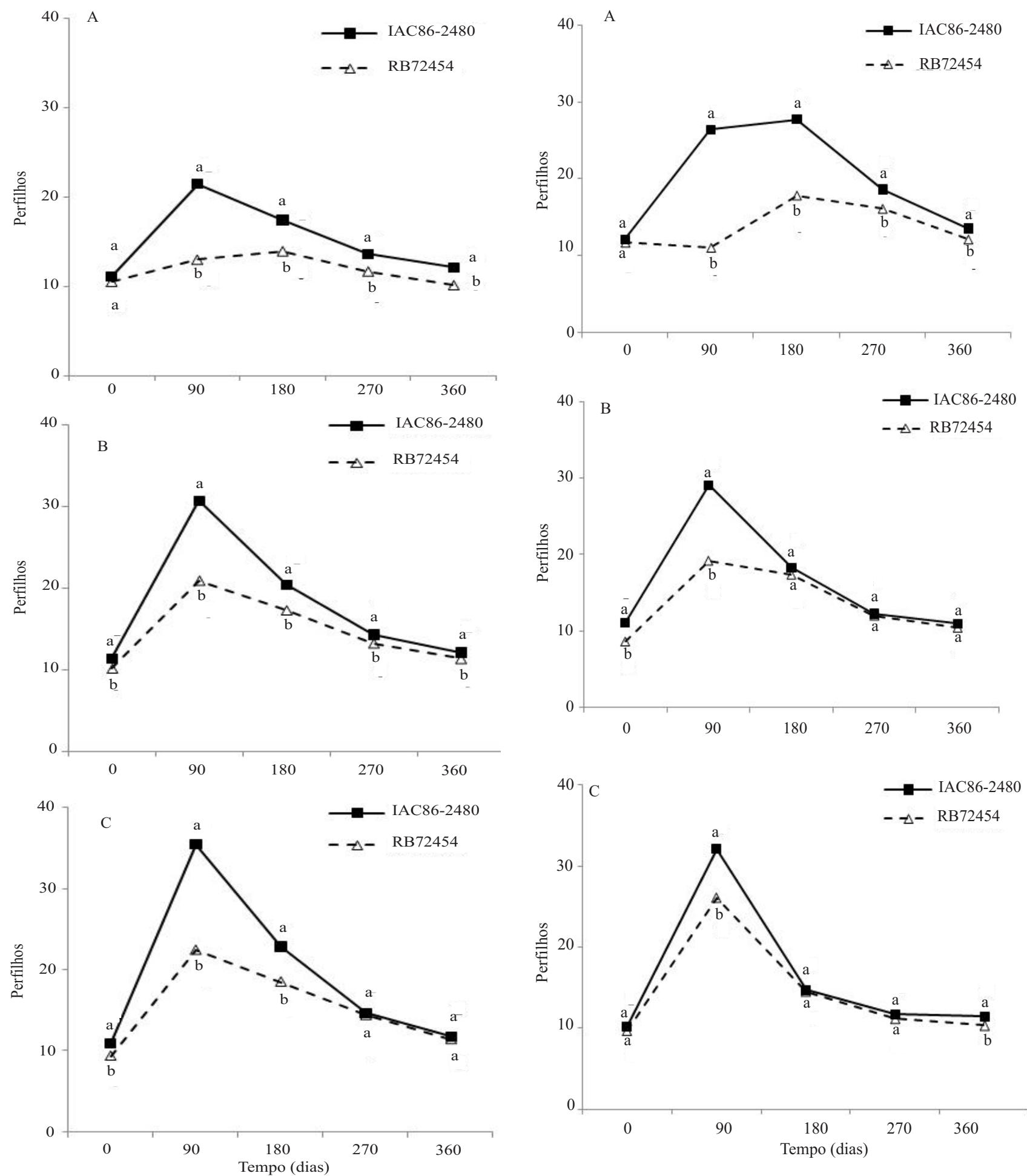

Figura 2. Número de perfilhos por metro linear, dos genótipos IAC86-2480 e RB72454, no período de 0 a 12 meses de idade, em relação a três alturas de corte acima do nível do solo: (A) $0 \mathrm{~cm}$; (B) $10 \mathrm{~cm}$; e(C) $20 \mathrm{~cm}$. Símbolos com letras iguais, na mesma data, não diferem entre si pelo teste de Tukey, a 5\% de probabilidade.

Figura 3. Número de perfilhos por metro linear, dos genótipos IAC86-2480 e RB72454, no período de 0 a 12 meses de idade, em relação a três épocas de colheita: (A) maio; (B) julho; e (C) setembro. Símbolos com letras iguais, na mesma data, não diferem entre si pelo teste de Tukey, a 5\% de probabilidade. 

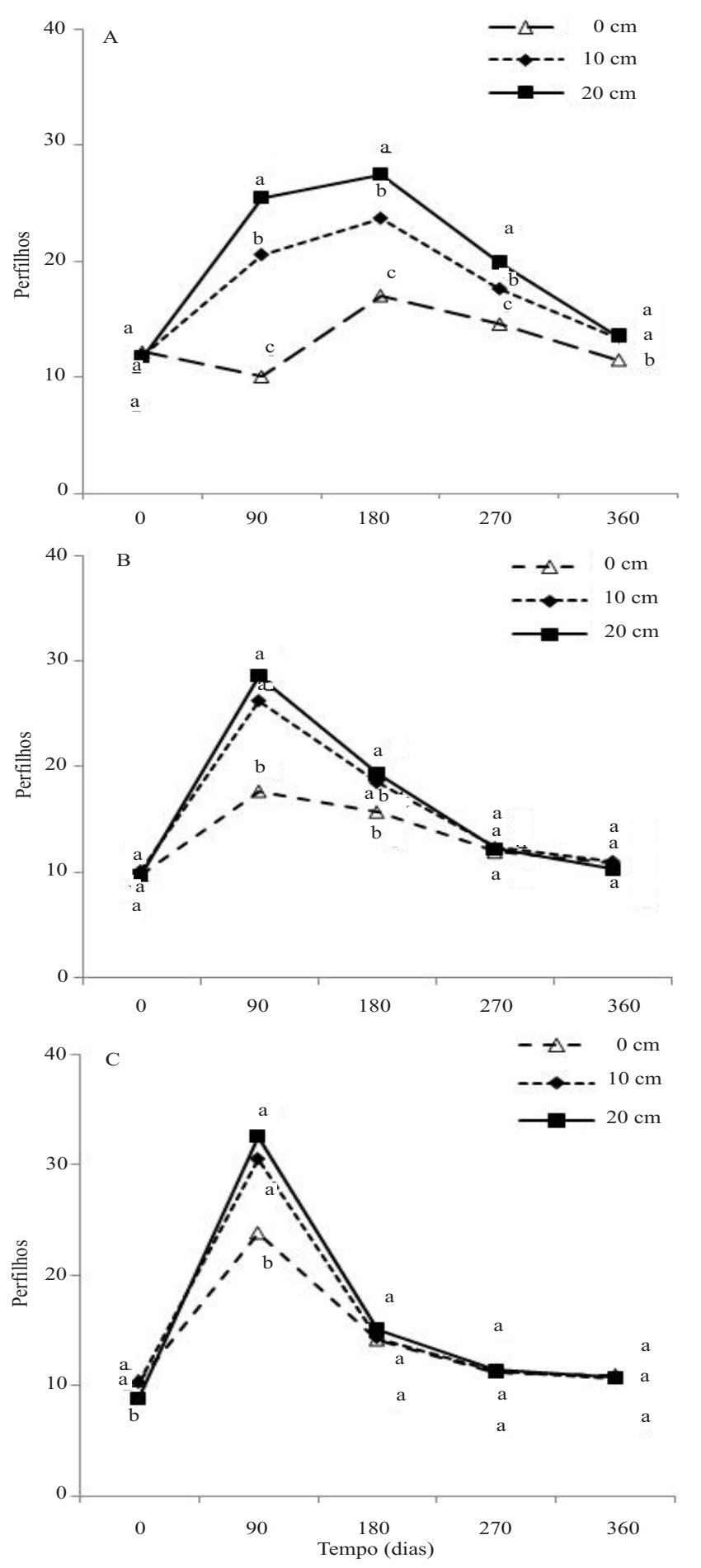

Figura 4. Número de perfilhos por metro linear, de canade-açúcar cortada em três alturas diferentes em relação ao solo, no período de 0 a 12 meses de idade, em relação a três épocas de colheita: (A) maio, (B) julho e (C) setembro. Símbolos com letras iguais, na mesma data, não diferem entre si pelo teste de Tukey, a 5\% de probabilidade. época), os cortes feitos a 10 e $20 \mathrm{~cm}$ tiveram perfilhamento semelhante aos $90 \mathrm{DAT}$, e superior àquele realizado a $0 \mathrm{~cm}$. Aos 180 DAT, houve diferença significativa apenas entre o corte feito a $20 \mathrm{~cm}$ e o realizado rente ao solo. A partir de então, não houve mais diferenças entre os tratamentos. Na colheita realizada em setembro, foi observada diferença dos cortes a 10 e $20 \mathrm{~cm}$, em relação ao rente ao solo, apenas aos 90 DAT. Portanto, nas condições em que os cortes foram efetuados, acima da superfície do solo (10 e $20 \mathrm{~cm}$ ), houve sobra de reserva energética disponível nos colmos (tocos), para ser utilizada pelas plantas para a rebrota. Assim, à medida que as condições climáticas foram desfavoráveis (Figura 1), maior foi o benefício proporcionado pela reserva energética dos colmos restantes, com o corte a 10 e $20 \mathrm{~cm}$.

Os genótipos diferiram significativamente entre si, quanto à produtividade, o que mostra a influência do material genético na variação da produtividade agrícola e industrial, em conseqüência da época de colheita. Além disso, a alocação adequada de cultivares para a agroindústria açucareira pode representar uma melhor exploração agrícola e resultar em maiores rendimentos econômicos (Tabela 2). Atualmente, há

Tabela 2. Produtividade de cana, em toneladas de cana por hectare (TCH), teor de sacarose na cana, em pol cana (PCC), fibra na cana, açúcar teórico recuperável(ATR) e produtividade de açúcar, em toneladas de pol por hectare $(\mathrm{TPH})$ em relação aos genótipos, altura de corte e época de colheita ${ }^{(1)}$.

\begin{tabular}{|c|c|c|c|c|c|}
\hline Tratamento & TCH & PCC & $\begin{array}{c}\text { Fibra } \\
(\%)\end{array}$ & $\begin{array}{c}\text { ATR } \\
\left(\mathrm{kg} \mathrm{Mg}^{-1}\right)\end{array}$ & ТPH \\
\hline \multicolumn{6}{|l|}{ Genótipo } \\
\hline IAC86-2480 & $78,18 b$ & $15,69 \mathrm{a}$ & $12,31 \mathrm{a}$ & $153,92 \mathrm{a}$ & $12,28 b$ \\
\hline RB72454 & & $15,80 \mathrm{a}$ & $12,22 \mathrm{a}$ & 154, & $14,42 \mathrm{a}$ \\
\hline \multicolumn{6}{|l|}{ Altura de corte $(\mathrm{cm})$} \\
\hline 0 & $82,61 \mathrm{a}$ & $15,74 \mathrm{a}$ & $12,22 \mathrm{a}$ & $154,30 \mathrm{a}$ & $13,15 \mathrm{a}$ \\
\hline 10 & $85,17 \mathrm{a}$ & $15,69 \mathrm{a}$ & $12,28 \mathrm{a}$ & $153,96 a$ & $13,40 \mathrm{a}$ \\
\hline 20 & $84,94 \mathrm{a}$ & $15,80 \mathrm{a}$ & $12,30 \mathrm{a}$ & $154,89 \mathrm{a}$ & $13,48 \mathrm{a}$ \\
\hline \multicolumn{6}{|l|}{ Época de colheita } \\
\hline Maio & $81,32 b$ & $13,07 \mathrm{c}$ & $11,66 \mathrm{c}$ & $130,30 \mathrm{c}$ & $10,66 \mathrm{c}$ \\
\hline Julho & $81,10 \mathrm{~b}$ & $16,40 \mathrm{~b}$ & $12,25 \mathrm{~b}$ & $160,30 \mathrm{~b}$ & $13,32 b$ \\
\hline Setembro & $90,31 \mathrm{a}$ & $17,77 \mathrm{a}$ & $12,89 \mathrm{a}$ & $172,54 \mathrm{a}$ & $16,06 \mathrm{a}$ \\
\hline \multicolumn{6}{|l|}{ Quadrados médios } \\
\hline Bloco & $117,00^{\mathrm{ns}}$ & $0,99 *$ & $0,69^{\text {ns }}$ & $76,44^{*}$ & $4,03^{\mathrm{ns}}$ \\
\hline Genótipo $(\mathrm{G})$ & $2.642,91^{*}$ & $0,20^{\mathrm{ns}}$ & $0,13^{\mathrm{ns}}$ & $15,24^{\mathrm{ns}}$ & $82,24^{*}$ \\
\hline Altura de corte (A) & $48,24^{\mathrm{ns}}$ & $0,64^{\mathrm{ns}}$ & $0,35^{\mathrm{ns}}$ & $5,31^{\mathrm{ns}}$ & $0,72^{\mathrm{ns}}$ \\
\hline Época de colheita (E) & $662,18^{*}$ & $140,31 *$ & $9,14^{*}$ & $11.338,66^{*}$ & $175,17^{*}$ \\
\hline GxA & $72,16^{\mathrm{ns}}$ & $0,36^{\mathrm{ns}}$ & $0,13^{\mathrm{ns}}$ & & $1,25^{\mathrm{ns}}$ \\
\hline GxE & $332,57^{*}$ & $0,15^{\mathrm{ns}}$ & $0,19^{\mathrm{ns}}$ & $12,38^{\mathrm{ns}}$ & $13,59 *$ \\
\hline $\mathrm{AxE}$ & $80,28^{\mathrm{ns}}$ & $0,15^{\mathrm{ns}}$ & $0,26^{\mathrm{ns}}$ & $11,04^{\mathrm{ns}}$ & $2,29^{\text {ns }}$ \\
\hline GxExA & $15,14^{\mathrm{ns}}$ & $0,33^{\text {ns }}$ & $0,29^{\text {ns }}$ & $3,41^{\mathrm{ns}}$ & $0,46^{\mathrm{ns}}$ \\
\hline CV (\%) & 10,30 & 3,26 & 3,64 & 2,95 & 11,52 \\
\hline
\end{tabular}

${ }^{(1)}$ Médias seguidas de letras iguais na coluna, em cada atributo (genótipo, altura de corte e época de colheita), não diferem entre si pelo teste de

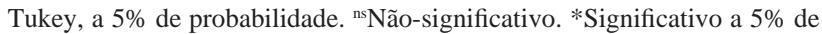
probabilidade. 
diversas variedades com diferentes características, que se adaptam ou não às adversidades durante o cultivo $\mathrm{e}$ o ciclo da cultura (Silva et al., 2004). Não se verificou efeito de genótipos e altura de corte nos atributos teor de sacarose, fibra na cana e ATR. No entanto, a época de colheita afetou esses atributos; a colheita feita em setembro proporcionou maiores valores que as realizadas em julho e maio, provavelmente pelas condições ambientais estressantes, como temperaturas mais baixas e ausência de chuva, que antecederam a colheita em setembro (Figura 1) e favoreceram a qualidade tecnológica dos colmos. O genótipo IAC86-2480 apresentou, em média, maior número de perfilhos aos 360 dias (Tabela 1), porém não foi o mais produtivo em açúcar por hectare (Tabela 2), justamente em razão da menor produtividade de colmos.

O maior perfilhamento nas primeiras avaliações (90 e 180 DAT), causado por cortes do colmo a 10 e $20 \mathrm{~cm}$ acima da superfície do solo (Figura 4), não promoveu efeito na produtividade final de colmos (Tabela 2). Entretanto, segundo Silva et al. (2007) e Wiedenfeld (2003), o crescimento inicial rápido e uniforme leva a atingir um bom estande, o que possibilita o rápido fechamento de entrelinha e o controle mais efetivo das plantas daninhas, além da cobertura homogênea do solo, que promove eficiente aproveitamento da energia luminosa pela planta.

A produtividade obtida pela interação entre genótipo e época de colheita está apresentada na Tabela 3. Não foi verificada diferença significativa $(\mathrm{p}>0,05)$ quanto à produtividade agrícola média do 'IAC86-2480', entre as três épocas de colheita. Entretanto, para o 'RB72454', a colheita realizada em setembro proporcionou maior produtividade do que as colheitas de maio e julho.

Tabela 3. Desdobramento da interação genótipo x épocas de corte, referente à produtividade de colmos e à produtividade de açúcar ${ }^{(1)}$.

\begin{tabular}{lcc}
\hline Época de corte & \multicolumn{2}{c}{ Genótipos } \\
\cline { 2 - 3 } & \multicolumn{2}{c}{ IAC86-2480 } \\
\hline & Produtividade de colmos $\left(\mathrm{Mg} \mathrm{ha}^{-1}\right)$ \\
Maio & $79,16 \mathrm{aA}$ & $83,49 \mathrm{bA}$ \\
Julho & $74,66 \mathrm{aB}$ & $87,53 \mathrm{bA}$ \\
Setembro & $80,73 \mathrm{aB}$ & $99,89 \mathrm{aA}$ \\
\hline & Produtividade de açúcar $\left(\mathrm{Mg} \mathrm{ha}^{-1}\right)$ \\
Maio & $10,34 \mathrm{cA}$ & $10,98 \mathrm{cA}$ \\
Julho & $12,26 \mathrm{bB}$ & $14,38 \mathrm{bA}$ \\
Setembro & $14,24 \mathrm{aB}$ & $17,89 \mathrm{aA}$ \\
\hline
\end{tabular}

${ }^{(1)}$ Médias seguidas de letras iguais, minúsculas na coluna e maiúsculas na linha, não diferem entre si pelo teste de Tukey, a 5\% de probabilidade.
Maule et al. (2001) estudaram o comportamento de nove cultivares de cana-de-açúcar e não constataram diferença de uma mesma cultivar, no estágio de cana-planta, quando colhida em três diferentes épocas, dentro de uma mesma safra, em dois locais com solos diferentes.

Quanto à produtividade de açúcar, por ser resultado tanto da produtividade de colmos quanto da concentração de sacarose, houve influência de genótipos e de épocas de colheita (Tabela 3). A variação foi crescente da primeira para a terceira época de colheita, e houve diferença entre as épocas. Entre genótipos não houve diferença nos valores de TPH em maio, porém em julho e setembro, os valores foram superiores no 'RB72454'.

A altura de corte não influenciou a produtividade final de açúcar (TPH), fator que é importante do ponto de vista da mecanização da colheita, pois, conceitualmente, quanto mais rente o corte ao solo, menores são as perdas agrícolas, entretanto, verificou-se que, em caso de altura de corte de colmos mais elevada, os pedaços de colmos restantes podem potencializar a rebrota da soqueira e garantir melhor padrão de perfilhamento.

Os resultados indicam que o desenvolvimento da cana-de-açúcar pode responder com maior perfilhamento inicial em cana-soca e maior produtividade, graças ao resíduo da altura de corte por colhedoras e época de colheita dos colmos. Sugere-se, portanto, que outros estudos sejam realizados, a fim de se obter informação da cultura em ciclos consecutivos de colheita, em diferentes anos agrícolas e tipos de solos, com avaliação do efeito da combinação desses fatores.

\section{Conclusões}

1. Genótipos decana-de-açúcarrespondemàalturade corte e à época de colheita dos colmos quanto ao perfilhamento, $\mathrm{e}$ respondem à época de colheita em relação à produtividade de colmos.

2. A reserva energética acumulada na base dos colmos, pela altura de corte, favorece a rebrota da cana-de-açúcar.

3. A época de colheita interfere na produtividade de colmos e de açúcar.

\section{Agradecimentos}

Ao Eng. Agrôn. Mário Percio Campana, do Centro de Cana APTA/IAC, pela colaboração no planejamento do experimento. 


\section{Referências}

CARNEIRO, A.E.V.; TRIVELIN, P.C.O.; VICTORIA, R.L. Utilização da reserva orgânica e de nitrogênio do tolete de plantio (colmo-semente) no desenvolvimento da cana-planta. Scientia Agricola, v.52, p.199-209, 1995.

CASAGRANDE, A.A. Tópicos de morfologia e fisiologia da cana-de-açúcar. Jaboticabal: Funep, 1991. 157p.

CASTRO, P.R.C.; CHRISTOFFOLETI, P.J. Fisiologia da cana-deaçúcar. In: MENDONÇA, A.F. Cigarrinhas da cana-de-açúcar: controle biológico. Maceió: Insecta, 2005. p.3-48.

GILBERT, R.A.; SHINE JUNIOR, J.M.; MILLER, J.D.; RICE, R.W.; RAINBOLT, C.R. The effect of genotype, environment and time of harvest on sugarcane yields in Florida, USA. Field Crops Research, v.95, p.156-170, 2006.

MARCHIORI, L.F.S. Influência da época de plantio e corte na produtividade da cana-de-açúcar. 2004. 277p. Tese (Doutorado) - Escola Superior de Agricultura Luiz de Queiroz, Piracicaba.

MAULE, R.F.; MAZZA, J.A.; MARTHA JUNIOR, G.B. Produtividade agrícola de cultivares de cana-de-açúcar em diferentes solos e épocas de colheita. Scientia Agricola, v.58, p.295-301, 2001.

PRADO, H. do. Solos do Brasil: gênese, morfologia, classificação, levantamento e manejo. 3.ed. Piracicaba, 2003. 275p.
REZENDE SOBRINHO, E.A. Comportamento de variedades de cana-de-açúcar em Latossolo Roxo, na região de Ribeirão Preto-SP. 2000. 85p. Dissertação (Mestrado) - Universidade Estadual Paulista, Jaboticabal.

SILVA, M. de A.; CARLIN, S.D.; CAMPANA, M.P.; LANDELL, M.G.A.; PERECIN, D.; VASCONCELOS, A.C.M. Brotação da cana-de-açúcar em condições de casa de vegetação. STAB: Açúcar Álcool e Subprodutos, v.22, p.28-31, 2003.

SILVA, M. de A.; CARLIN, S.D.; PERECIN, D. Fatores que afetam a brotação inicial da cana-de-açúcar. Revista Ceres, v.51, p. 457-466, 2004.

SILVA, M. de A.; GAVA, G.J. de C.; CAPUTO, M.M.; PINCELLI, R.P.; JERÔNIMO, E.M.; CRUZ, J.C.S. Uso de reguladores de crescimento como potencializadores do perfilhamento e da produtividade em cana-soca. Bragantia, v.66, p.545-552, 2007.

SOUZA, Z.M. de; PRADO, R. de M.; PAIXÃO, A.C.S.; CESARIN, L.G. Sistemas de colheita e manejo da palhada de canade-açúcar. Pesquisa Agropecuária Brasileira, v.40, p.271-278, 2005.

WIEDENFELD, B. Enhanced sugarcane establishment using plant growth regulators. Journal of American Society of Sugarcane Technologists, v.23, p.48-61, 2003.

Recebido em 29 de fevereiro de 2008 e aprovado em 30 de julho de 2008 